\title{
TARDINESS BASED NEW DISPATCHING RULES FOR SHOP SCHEDULING WITH UNRELIABLE MACHINES
}

\author{
Singh, A.; Mehta, N. K. \& Jain, P. K. \\ Department of Mechanical \& Industrial Engineering \\ Indian Institute of Technology Roorkee, Roorkee-247667, India \\ E-mail: amolsdme@iitr.ernet.in; mehtafme@iitr.ernet.in; pjainfme@iitr.ernet.in
}

\begin{abstract}
In this research paper a comparative study has been made of tardiness based existing as well as new dispatching rules. Mean tardiness, maximum tardiness and the number of tardy jobs objectives have been used to evaluate the performance of each dispatching rule. Several experimental parameters related to shop loading levels, breakdown levels and mean time to repair are taken into consideration to analyse the effect of these parameters on the performance of the various dispatching rules. Simulation results indicate that shop loading, breakdown level and mean time to repair are important parameters for the selection of an appropriate rule in a shop.
\end{abstract}

Key Words: Tardiness, Dispatching Rules, Busy Time Approach, Inter Breakdown Time, Repair Time.
Notations
$C$ - due date allowance factor
$C_{i}$ - completion time of job $i$
$D_{i}$ - due date of job $i$
$\tau$ - time at which dispatching decision is made
$p_{i j}$ - processing time for operation $j$ of job $i$
$Z_{i}-$ priority index of job $i$
$n_{i}$ - total number of operations needed for job $i$
$A_{i}$ - arrival time of job $i$ on the shop floor
$t_{j} \quad$ - time at which job enters in the queue for its $j^{\text {th }}$ operation.

\section{INTRODUCTION}

Scheduling has been defined as the allocation of resources over time to perform a collection of tasks. The resources in a manufacturing system may be machines, labour and storage space etc, while the tasks may be production tasks and material handling tasks etc. Each task generally has an associated earliest possible start time, priority level, duration and due date. The objective of the scheduling process is to determine the start/end times for the individual tasks to optimize a specified performance measure, subject to resources capacity constraints. Scheduling may be static or dynamic. In static scheduling it is assumed that the number of jobs, their processing sequence and the respective processing times are known a priori. However, in real-life situation there are lot many uncertainties associated with part arrival, processing time and machine availability. In view of the dynamic nature of manufacturing systems, dynamic scheduling approach has been advocated, as it helps prepare schedules in real time by taking into consideration the actual status of the system resources. In most of the scheduling problems it is assumed that the machines are continuously available for processing and there is no interruption on the machines. But in actual practice machines are not continuously available due to breakdowns on the shop floor. Schedules without considering 
the actual status of the shop floor are produced in advance. Unfortunately very often, no sooner the schedule is reached to the shop floor it is subjected to random disruptions, which make the initial schedule obsolete. To overcome this problem it is necessary to confirm the flow of parts according to the actual status of the shop floor.

Generally the rules EDD and SLACK perform well in light load conditions, whereas SPT performs well in tight load conditions with loose due dates [1, 2]. Some rules like modified due date (MDD) and modified operation due dates (MOD) utilize operation due dates [3, 4]. Total work content method has been suggested for defining the operational due dates [5]. The priority index of MDD rule is defined as its original due date or its earliest finish time which ever is larger, whereas the priority index of MOD is defined as its original operational due date ODD or its earliest finish time whichever is larger. These rules have been used in the minimization of tardiness-based objectives. Another popular rule is COVERT that was specially developed for minimizing the tardiness-based objectives [6]. The COVERT priority index represents the expected incremental tardiness cost per unit of imminent processing time. The expected tardiness is a relative measure of how much tardiness a job might experience if it is delayed by one time unit. Raghu and Rajendran [7] proposed RR rule for the minimization of mean tardiness. This rule performs well under a variety of shop floor conditions, if proper weights are assigned to component of process time and due date of a job.

Anderson [8] proposed two rules CR+SPT and S/RPT+SPT for the minimization of tardiness-based objectives. Jayamohan et al. [9] made a comparative simulation study between best existing and their proposed rules. They concluded that for the minimization of tardiness-based objectives, PT+PW, PT+PW+FDD, PT+PW+ODD, FDD and ODD rules perform better than other rules.

Several simulation studies on dispatching rules have been reported in literature [8-17]. In most of the studies it is assumed that machines in the shop are continuously available (there are no interruptions on the machines). Oliver Holthaus [14] studied the effect of breakdown parameter on the performance of the dispatching rules. For the simulation study two models of a manufacturing system were developed. In the first model, it was assumed that the machines are continuously available and in the second model, machine breakdowns were considered. Different values of breakdown parameter and utilization level were used for analysing the effect of these parameters with respect to tardiness-based objectives such as mean and maximum tardiness and number of tardy jobs.

Queuing theory that uses the dispatching rules for selecting a job from the queue for its processing is the most popular technique for solving the dynamic scheduling problems. The performance of a manufacturing system depends on the selection of efficient dispatching rules with respect to an objective function. A need exists to develop efficient dispatching rules that can provide high performance in real life manufacturing system. The present work is an attempt in this direction by analysing the effect of different breakdown parameters and shop loading conditions on the performance of various dispatching rules.

As mentioned before, in the present study, tardiness based performance measures have been considered for evaluating the relative performance of the dispatching rules. The basic objective of tardiness based performance measures is to complete all jobs in due time. If the completion time of job $i$ exceeds its due date, then job $i$ is said to be a tardy job and the amount of time by which the completion time of job $i$ exceeds its due date is called as the tardiness of job $i$. The tardiness $T_{i}$ of job $i$ is calculated as $T_{i}=\max \left(0, C_{i}-D_{i}\right)$. The total tardiness of all jobs on the shop floor is defined as:

$$
\sum_{i=1}^{N} \max \left(0, C_{i}-D_{i}\right)
$$

where $C_{i}$ and $D_{i}$ are the completion time and due date of job $i$ respectively, and $N$ is the total number of jobs under consideration. 
Several important tardiness based performance measures as used for minimization in the present work are defined as:

- Mean tardiness: $\bar{T}=\left(\sum_{i=1}^{N} T_{i}\right) / N$

- $\quad$ Maximum tardiness: $T_{\max }=\max \left(T_{i} ; 1<i<N\right)$

- Percentage of tardy jobs: $\% N_{t}=\left(i, T_{i}>0,1<i<N\right) / N \times 100$

\section{DISPATCHING RULES}

In the present study, five new tardiness based dispatching rules have been proposed as given below:

\section{1 (WTIS) max $_{\text {(Waiting Time In System) }}$ max rule}

A new concept of waiting time in system has been proposed in this paper. The total waiting time of job $i$ up to the operation $j$ in the system is calculated as follows:

$$
W T I S_{i j}=\tau-A_{i}-\sum_{k=1}^{j-1} p_{i k}
$$

The jobs are prioritised in decreasing order of WTIS $\mathrm{Wij}_{\mathrm{ij}}\left(\right.$ i.e. $\left.Z_{i}=\left(W T I S_{i j}\right)_{\max }\right)$ for minimizing the mean tardiness.

\section{2 (WTIS/PT) $)_{\min }(\text { Waiting Time In System/Process Time) })_{\min }$ rule}

Waiting time in system for $i^{\text {th }}$ job up to its $j^{\text {th }}$ operation per process time of the $j^{\text {th }}$ operation is calculated as given below:

$$
(\mathrm{WTIS} / \mathrm{PT})_{i j}=\left(\tau-A_{i}-\sum_{k=1}^{j-1} p_{i k}\right) / p_{i j}
$$

The priority index $\left(Z_{i}\right)$ of this rule is given as below:

$$
Z_{i}=\left((W T I S / P T)_{i j}\right)_{\min }
$$

i.e. the job with minimum value of WTIS/PT is chosen for loading for minimizing the number of tardy jobs and mean tardiness.

\section{3 (WTIS/PT) $)_{\max }$ (Waiting Time In System/Process Time) $)_{\max }$ rule}

The priority index $\left(Z_{i}\right)$ of this rule is given as below:

$$
Z_{i}=\left((W T I S / P T)_{i j}\right)_{\max }
$$

The job with maximum value of WTIS/PT is chosen for loading for minimizing the mean tardiness and maximum tardiness simultaneously.

\subsection{WTIS/(TPT-RPT) (Waiting Time In System/(Total Processing Time-Remaining Processing Time Excluding $\mathrm{j}^{\text {th }}$ Operation)) rule}

The WTIS/(TPT-RPT) for $\mathrm{i}^{\text {th }}$ job up to its $\mathrm{j}^{\text {th }}$ operation is calculated as below:

$$
(W T I S / T P T-R P T)_{i j}=\left(\tau-A i-\sum_{k=1}^{j-1} p_{i k}\right) /\left(\sum_{k=1}^{j} p_{i k}\right)
$$

The priority index $Z_{i}$ for this rule is given as below:

$$
Z_{i}=\left((W T I S / T P T-R P T)_{i j}\right)_{\text {min }}
$$


The job with minimum value of $Z_{i}$ is chosen for loading. This rule minimizes the value of mean tardiness and the number of tardy jobs simultaneously.

\subsection{ODD + (WTIS/(TPT-RPT)) (Operational Due Date + Waiting Time In System/(Total Processing Time-Remaining Processing Time Excluding $j^{\text {th }}$ Operation)) rule}

The priority index for this rule is calculated as below:

$$
Z_{i}=O D D_{i j}+\left(\tau-A_{i}-\sum_{k=1}^{j-1} p_{i k}\right) /\left(\sum_{k=1}^{j} p_{i k}\right)
$$

The job with minimum value of $Z_{i}$ is chosen for loading for minimizing maximum tardiness.

In all the above rules in case of any tie in the value of $Z_{i}$ for more than one waiting parts, FIFO (first in first out) rule is used for breaking the tie.

The performance of these rules is evaluated later in the paper against the rules given in Table I, wherein three standard benchmark rules and 3 best existing dispatching rules according to $[6,7,20]$ have been considered.

Table I: List of best existing scheduling rules.

\begin{tabular}{|c|ccc|}
\hline Author & Rule & Description & Recommended application \\
\hline Conway [19] & FIFO & $Z_{i}=t_{j}$ & Min. of $T_{\max }$ \\
Conway [19] & SPT & $Z_{i}=p_{i j}$ & Min. of $\% N_{t}$ \\
Conway [19] & EDD & $Z_{i}=D_{i}$ & Min. of $T_{\max }$ \\
Jayamohan \& & PT+PW & $Z_{i}=p_{i j}+\left(\tau-t_{j}\right)$ & Min. of $\bar{T}$ and $\% N_{t}$ \\
Rajendran [9] & ODD & $Z_{i}=A_{i}+c \times \sum_{k=1}^{j} p_{i k}$ & Min. of $T_{\max }$ \\
Kanet \& Hayya [5] & ODD & - \\
Jayamohan \& & PT + PW + & $Z_{i}=p_{i j}+\left(\tau-t_{j}\right)+$ & Min. of $T$ and $\% N_{t}$ \\
Rajendran [9] & ODD & OD $D_{i j}$ & \\
\hline
\end{tabular}

\section{SIMULATION MODELLING FOR EVALUATION OF DISPATCHING RULES}

In the simulation study a shop with 10 machines and 16-job types has been considered. The number of operation for each job type is sampled from a uniform distribution in the range of 3-9. Routings and percentage of production volume of each job type is generated randomly as shown in Table II. Process times are sampled from a uniform distribution in the range 1-9. Job arrivals follow an exponential distribution. If $\bar{P}$ represents the mean processing time of a job, $M$ is the total number of machines in the shop and $U_{s}$ the shop utilization then mean interarrival time of parts can be decided by the relationship [14]:

$$
\lambda=\bar{P} /\left(M \times U_{s}\right)
$$

Four levels of shop utilization viz. $80 \%, 85 \%, 90 \%$ and $95 \%$ have been simulated in the present work $[6,18]$. The total work content method has been chosen for setting the due dates with an allowance factor of 3 and 6 [2]. The due date $\left(D_{i}\right)$ for each part type is calculated as:

$$
D_{i}=A_{i}+\left(C \times \sum_{k=1}^{n_{i}} P_{i k}\right)
$$


Table II: Processing sequence data.

\begin{tabular}{|c|c|c|c|c|c|c|c|c|c|c|}
\hline \multirow{2}{*}{$\begin{array}{l}\text { Job } \\
\text { type }\end{array}$} & \multicolumn{9}{|c|}{ Operation Sequence } & \multirow{2}{*}{$\begin{array}{l}\text { Production } \\
\text { Volume \% }\end{array}$} \\
\hline & 1 & 2 & 3 & 4 & 5 & 6 & 7 & 8 & 9 & \\
\hline 1 & $\mathrm{M}_{1}(8)$ & $M_{5}(5)$ & $\mathrm{M}_{9}(7)$ & & & & & & & 7 \\
\hline 2 & $M_{2}(6)$ & $\mathrm{M}_{3}(2)$ & $M_{4}(5)$ & $\mathrm{M}_{5}(4)$ & $M_{6}(3)$ & $M_{7}(5)$ & $M_{8}(6)$ & $\mathrm{M}_{9}(5)$ & $\mathrm{M}_{10}(4)$ & 6 \\
\hline 3 & $M_{3}(7)$ & $M_{6}(1)$ & $M_{7}(9)$ & $M_{8}(7)$ & & & & & & 6 \\
\hline 4 & $\mathrm{M}_{2}(8)$ & $M_{4}(5)$ & $\mathrm{M}_{6}(7)$ & $M_{10}(6)$ & & & & & & 6 \\
\hline 5 & $\mathrm{M}_{1}(3)$ & $M_{3}(8)$ & $\mathrm{M}_{5}(2)$ & $M_{6}(6)$ & $\mathrm{M}_{9}(7)$ & $M_{8}(4)$ & $\mathrm{M}_{10}(1)$ & $M_{7}(8)$ & & 7 \\
\hline 6 & $\mathrm{M}_{4}(9)$ & $M_{2}(2)$ & $\mathrm{M}_{3}(3)$ & $\mathrm{M}_{10}(2)$ & $\mathrm{M}_{8}(1)$ & $\mathrm{M}_{9}(7)$ & $\mathrm{M}_{6}(1)$ & $\mathrm{M}_{7}(8)$ & & 6 \\
\hline 7 & $M_{7}(4)$ & $M_{1}(2)$ & $\mathrm{M}_{10}(9)$ & $M_{3}(5)$ & $\mathrm{M}_{4}(3)$ & & & & & 6 \\
\hline 8 & $M_{8}(8)$ & $M_{4}(6)$ & $M_{6}(7)$ & $\mathrm{M}_{2}(5)$ & $M_{1}(6)$ & & & & & 7 \\
\hline 9 & $M_{3}(9)$ & $M_{7}(6)$ & $\mathrm{M}_{4}(7)$ & $M_{6}(5)$ & $M_{5}(4)$ & & & & & 6 \\
\hline 10 & $\mathrm{M}_{6}(3)$ & $M_{2}(4)$ & $M_{8}(8)$ & $M_{7}(2)$ & $M_{3}(6)$ & $M_{4}(5)$ & $\mathrm{M}_{5}(2)$ & & & 6 \\
\hline 11 & $\mathrm{M}_{9}(4)$ & $\mathrm{M}_{6}(3)$ & $\mathrm{M}_{7}(4)$ & $\mathrm{M}_{8}(7)$ & $M_{5}(3)$ & $M_{3}(6)$ & $\mathrm{M}_{4}(4)$ & & & 6 \\
\hline 12 & $\mathrm{M}_{5}(4)$ & $\mathrm{M}_{7}(9)$ & $\mathrm{M}_{1}(1)$ & $\mathrm{M}_{2}(6)$ & $\mathrm{M}_{6}(7)$ & $\mathrm{M}_{4}(3)$ & $M_{3}(5)$ & & & 7 \\
\hline 13 & $M_{7}(5)$ & $M_{9}(4)$ & $\mathrm{M}_{10}(3)$ & $\mathrm{M}_{5}(8)$ & $\mathrm{M}_{3}(2)$ & $M_{1}(5)$ & & & & 6 \\
\hline 14 & $\mathrm{M}_{10}(6)$ & $\mathrm{M}_{8}(7)$ & $\mathrm{M}_{2}(9)$ & $\mathrm{M}_{9}(2)$ & $\mathrm{M}_{4}(3)$ & $\mathrm{M}_{6}(1)$ & & & & 6 \\
\hline 15 & $M_{3}(4)$ & $M_{9}(9)$ & $\mathrm{M}_{8}(8)$ & $M_{1}(1)$ & $\mathrm{M}_{7}(6)$ & $\mathrm{M}_{5}(3)$ & & & & 6 \\
\hline 16 & $\mathrm{M}_{4}(6)$ & $M_{6}(5)$ & $\mathrm{M}_{9}(4)$ & $\mathrm{M}_{10}(5)$ & $\mathrm{M}_{8}(7)$ & $\mathrm{M}_{2}(5)$ & & & & 6 \\
\hline
\end{tabular}

(Figures in parentheses are the processing times.)

Time between failure MTBF and mean time to repair MTTR are assumed to follow Gamma distribution. A busy time approach has been used for generating the breakdown times (i.e. machines fail only while performing an operation on a job). Law and Kelton [20] suggested that in the absence of real time data, busy time distribution is most likely to be a Gamma distribution with a shape parameter of 0.7. They also suggested that Gamma distribution with a shape parameter of 1.4 is appropriate for generating the repair time. Thus the busy time between two successive failures (which is inter-breakdown time) is assumed to follow a Gamma distribution with $\alpha=0.7$ and $\beta=M T T R \times \mathrm{e} /$ (1-e) $\times 0.7$ and the duration of each breakdown (i.e. repair time) is assumed to follow a Gamma distribution with $\alpha=1.4$ and $\beta=M T T R / 1.4$.

Where, $e=M T B F /(M T B F+M T T R)$

Similarly, machine breakdown level $B L_{s}$ is defined by the ratio of MTTR over the sum of MTTR and MTBF as given below.

$$
B L_{s}=M T T R / M T T R+M T B F
$$

where $B L_{s}$ represents the percentage downtime of a machine. In the present study, the effects of breakdown level and mean time to repair on the performance of dispatching rules have been evaluated by considering three values of breakdown levels $B L_{s}$ (i.e. $0 \%, 2.5 \%$ and $5 \%$ ) and three values of MTTR (i.e. $\stackrel{-}{P}, 2.5 \bar{P}$ and $5 \bar{P}$ ).

The simulation studies have been conducted for twenty replications for a run of 200 hours each and with a warm-up period of 35 hours each.

\section{TARDINESS BASED PERFORMANCE ANALYSIS}

In the following sections relative performances of 11 dispatching rules with respect to tardiness based objectives such as minimization of mean tardiness $(\bar{T})$, minimization of maximum tardiness $\left(T_{\max }\right)$ and minimization of percentage of tardy jobs have been analysed by assuming different values of breakdown parameters and two values of due date tightness. In this analysis three values of breakdowns level $B L_{s}$ (i.e. $0 \%, 2.5 \%$ and $5 \%$ ), three values 
of mean time to repair MTTR (i.e. $\bar{P}, 2.5 \bar{P}$ and $5 \bar{P}$ ) and two values of due date tightness (i.e. $C=3$ and $C=6$ ) have been considered to analyse the effect of each parameter on the performance of the dispatching rules. If $X$ is a set of all considered dispatching rules (i.e. 11) and ${ }_{T}^{-}(x)$ is the mean tardiness of rule $x, \forall x \varepsilon X$, then

$$
\bar{T}_{\min }=\operatorname{Min}\left(\bar{T}\left(x_{i}\right)\right) \text {, where } i=1 \ldots 11
$$

The relative percentage increase (RPI) value of a rule $x$ is calculated as follows:

$$
R P I(\stackrel{-}{T}(x))=\left(\left(T_{T}^{-}(x)-{ }_{T}^{-} \text {min }\right) /\left({ }_{T}^{-} \text {min }\right)\right) \times 100 \% \text {, where } x \in X
$$

The lower is the RPI value the better is the system performance.

\subsection{Effect of utilization level on the relative performance of dispatching rules}

In this section, the relative performance of the dispatching rules for tardiness-based objectives has been analysed by taking different values of shop utilization for two values of due date tightness. In this analysis four values of shop utilization (i.e. $80 \%, 85 \%, 90 \%$ and $95 \%$ ) with two values of due date tightness (i.e. $C=3$ for tight due dates and $C=6$ for loose due dates) have been considered to evaluate the effect of these parameters on the performance of each dispatching rule. Table III shows that at light load condition WTIS/(TPT-RPT) is the best rule for tight due dates and ODD is the best rule for loose due dates for the minimization of mean tardiness.

\begin{tabular}{|c|c|c|c|c|c|c|c|c|c|c|c|c|}
\hline \multirow[t]{2}{*}{ Rule } & \multicolumn{3}{|c|}{$\mathrm{U}_{\mathrm{s}}=80 \%$} & \multicolumn{3}{|c|}{$\mathrm{U}_{\mathrm{s}}=85 \%$} & \multicolumn{3}{|c|}{$\mathrm{U}_{\mathrm{s}}=90 \%$} & \multicolumn{3}{|c|}{$\mathrm{U}_{\mathrm{s}}=95 \%$} \\
\hline & $\begin{array}{c}\text { RPI } \\
\bar{T} \\
(T)\end{array}$ & $\begin{array}{l}\text { RPI } \\
\left(T_{\text {max }}\right)\end{array}$ & $\% \mathrm{~N}_{\mathrm{t}}$ & $\begin{array}{c}\text { RPI } \\
\bar{T} \\
(T)\end{array}$ & $\begin{array}{l}\text { RPI } \\
\left(T_{\text {max }}\right)\end{array}$ & $\% \mathrm{~N}_{\mathrm{t}}$ & $\begin{array}{c}\text { RPI } \\
\overline{(T})\end{array}$ & $\begin{array}{l}\text { RPI } \\
\left(T_{\max }\right)\end{array}$ & $\% \mathrm{~N}_{\mathrm{t}}$ & $\begin{array}{c}\text { RPI } \\
\overline{(T})\end{array}$ & $\begin{array}{l}\text { RPI } \\
\left(T_{\max }\right)\end{array}$ & $\% \mathrm{~N}_{\mathrm{t}}$ \\
\hline \multicolumn{13}{|l|}{$C=3$} \\
\hline WTIS/(TPT-RPT) * & 0 & 560.60 & 31.29 & 1.70 & 325.61 & 33.27 & 2.62 & 262.58 & 35.21 & $67.15^{-}$ & 186.58 & 35.31 \\
\hline $\mathrm{PT}+\mathrm{PW}$ & 10.06 & 551.06 & 39.60 & 0 & 302.39 & 42.35 & 0 & 251.22 & 46.33 & 102.90 & 194.49 & 49.06 \\
\hline (WTIS/PT)min* & 16.70 & 580.91 & 35.39 & 35.95 & 374.06 & 37.89 & $15.35^{-}$ & 248.80 & 38.48 & 95.34 & 199.40 & 38.01 \\
\hline $\begin{array}{l}\text { ODD+(WTIS/(TPT- } \\
\text { RPT) }) *\end{array}$ & 78.48 & 17.55 & 86.34 & 139.78 & 18.07 & 90.81 & 175.09 & 19.56 & 93.63 & 472.67 & 19.63 & 96.03 \\
\hline ODD & 78.94 & 0 & 92.17 & 152.34 & 0.15 & 93.63 & 186.89 & 0.06 & 94.84 & 470.05 & 0.09 & 96.18 \\
\hline EDD & 85.81 & 0.23 & 89.58 & 160.63 & 0 & 91.07 & 193.44 & 0.06 & 92.88 & 478.77 & 0 & 94.84 \\
\hline $\mathrm{PT}+\mathrm{PW}+\mathrm{ODD}$ & 91.30 & 49.23 & 84.54 & 157.65 & 59.33 & 88.55 & 182.77 & 63.90 & 92.31 & 463.08 & 66.30 & 95.79 \\
\hline FIFO & 101.60 & 27.44 & 87.85 & 185.74 & 33.43 & 88.97 & 224.15 & 37.53 & 90.47 & 512.20 & 128.0 & 92.78 \\
\hline (WTIS)max* & 116.01 & 323.43 & 67.77 & 124.46 & 307.03 & 66.26 & 49.43 & 238.30 & 68.05 & 0 & 155.45 & 69.92 \\
\hline (WTIS/PT)max* & 116.47 & 317.02 & 69.15 & 121.27 & 299.72 & 70.03 & 68.91 & 221.03 & 71.90 & 20.93 & 160.72 & 72.39 \\
\hline SPT & 125.85 & 212.13 & 43.58 & 193.82 & 193.32 & 45.12 & 212.17 & 171.34 & 47.37 & 512.20 & 128.0 & 48.80 \\
\hline \multicolumn{13}{|l|}{$C=6$} \\
\hline ODD & 0 & 1.74 & 85.55 & 56.89 & 1.26 & 87.99 & 88.77 & 0.94 & 90.24 & 195.12 & 0.85 & 92.80 \\
\hline WTIS/(TPT-RPT) * & 1.75 & 591.29 & 15.57 & 7.4 & 337.61 & 17.25 & 11.70 & 270.21 & 18.95 & 43.98 & 190.97 & 19.07 \\
\hline EDD & 2.97 & 0 & 84.68 & 62.83 & 0 & 85.85 & 95.76 & 0 & 87.37 & 203.65 & 0 & 90.32 \\
\hline $\mathrm{PT}+\mathrm{PW}$ & 6.90 & 581.65 & 20.76 & 0 & 313.32 & 23.05 & 0 & 258.46 & 26.85 & 56.16 & 199.09 & 30.0 \\
\hline $\begin{array}{l}\text { ODD+(WTIS/(TPT- } \\
\text { RPT)) * }\end{array}$ & 9.06 & 18.96 & 74.60 & 58.24 & 18.98 & 81.08 & 86.65 & 20.04 & 86.77 & 202.58 & 20.21 & 91.45 \\
\hline FIFO & 12.31 & 28.60 & 83.48 & 77.97 & 34.39 & 84.59 & 117.90 & 38.60 & 85.01 & 244.59 & 43.47 & 87.32 \\
\hline (WTIS/PT)min* & 12.71 & 612.62 & 18.16 & 37.29 & 387.53 & 21.20 & 22.19 & 255.97 & 21.51 & 66.51 & 204.02 & 21.03 \\
\hline $\mathrm{PT}+\mathrm{PW}+\mathrm{ODD}$ & 19.75 & 51.67 & 70.08 & 76.62 & 60.96 & 76.63 & 101.10 & 65.71 & 82.08 & 205.02 & 67.27 & 89.10 \\
\hline SPT & 68.33 & 224.56 & 31.80 & 140.67 & 200.73 & 33.08 & 174.81 & 176.77 & 34.20 & 350.07 & 131.28 & 33.60 \\
\hline (WTIS/PT)max* & 124.89 & 335.57 & 37.23 & 145.40 & 311.53 & 38.13 & 94.26 & 227.95 & 39.33 & 5.71 & 164.52 & 35.69 \\
\hline (WTIS)max* & 129.09 & 342.47 & 35.89 & 189.45 & 319.11 & 31.33 & 95.01 & 245.76 & 32.92 & 0 & 159.22 & 30.46 \\
\hline
\end{tabular}

Table III: RPI values of 11 dispatching rules at $U_{s}=(80 \%, 85 \%, 90 \%$ and $95 \%)$.

(* Newly proposed dispatching rules)

At high utilization (WTIS) max $_{\text {is }}$ ise best and (WTIS/PT) max $_{\text {is }}$ is the next best rule for tight as well as loose due dates for the minimization of mean tardiness. The performance of (WTIS) $)_{\max }$ and (WTIS/PT) $)_{\max }$ rules with respect to mean tardiness at tight and loose due dates have been shown in Fig. 1 and Fig. 2 respectively. These two figures indicate that at utilization less than $90 \%$ these rules perform poorly although, at above $90 \%$ utilization the performance of these two rules drastically improves and at $95 \%$ utilization, their performance is the best. 
Mean tardiness for $c=6$

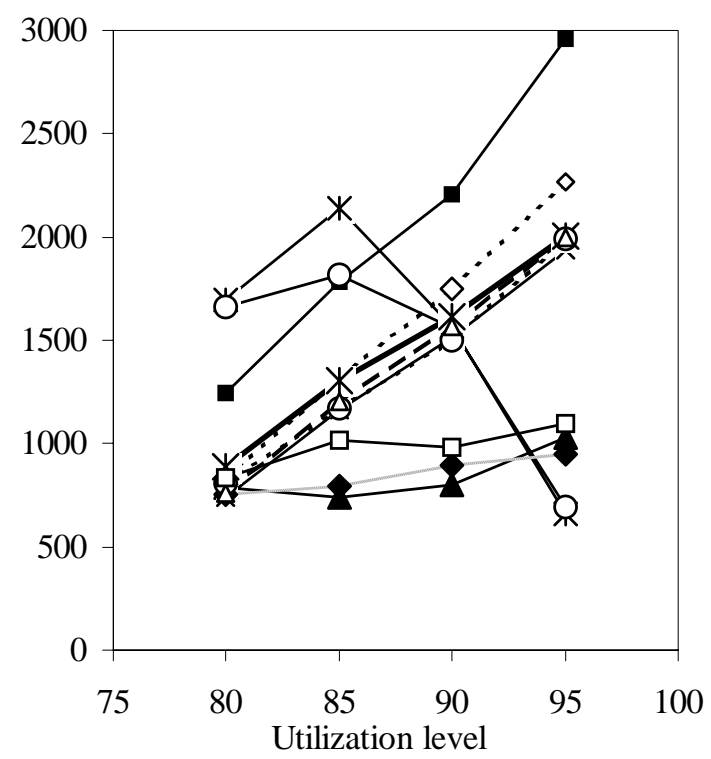

Figure 1: Mean tardiness vs. Utilization

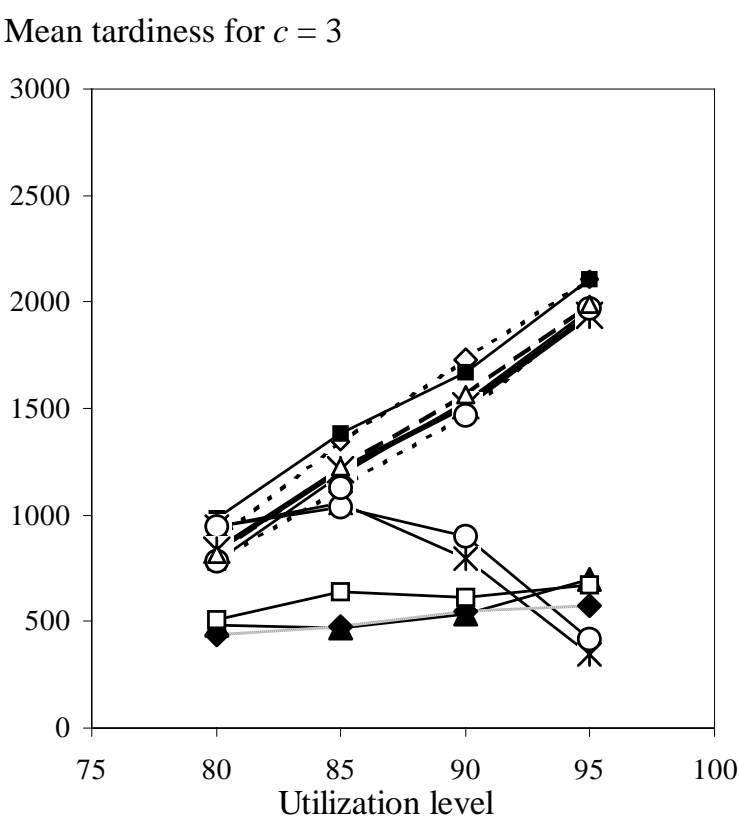

Figure 2: Mean tardiness vs. Utilization

\begin{tabular}{|c|c|c|}
\hline$\cdots \diamond-\cdots$ FIFO & $\longrightarrow \mathrm{SPT}$ & $\longrightarrow \mathrm{PT}+\mathrm{PW}$ \\
\hline$-x-O D D$ & 一*-(WTIS)max & $-\mathrm{O}$ (WTIS/PT)max \\
\hline$\checkmark$ WTIS/TPT-RPT & $-*-\mathrm{PT}+\mathrm{PW}+\mathrm{ODD}$ & - - - - - ODD+WTIS/TPT-RPT \\
\hline$--\Delta--\mathrm{EDD}$ & $\longrightarrow$ (WTIS/PT)min & \\
\hline
\end{tabular}

For the minimization of maximum tardiness, ODD is the best rule at low utilization for tight due dates whereas at high utilization and tight due dates, EDD is the best rule. For loose due dates, EDD followed by ODD and ODD+(WTIS/(TPT-RPT)) are the best rules at low as well as high utilization for the minimization of maximum tardiness. For the minimization of number of tardy jobs, WTIS/(TPT-RPT) is the best rule with (WTIS/PT) $\min$ as the second best rule for tight as well as loose due dates at all levels of shop utilization. The relative performance analysis of 11 dispatching rules with respect to the tardiness-based objectives indicates that the utilization level affects the relative performance of the dispatching rules.

\subsection{Effect of breakdown levels on the performance of dispatching rules}

Table IV presents the relative percentage increase in mean tardiness, maximum tardiness and percentage of tardy jobs for the 11 dispatching rules relative to the best performing rule at different breakdown levels. In this analysis, the effect of breakdown level is analysed by considering three values of breakdown levels by fixing the mean time to repair (MTTR) value at $2.5 \stackrel{P}{ }$ on both the tight and loose due dates. From Table IV, it can be observed that PT $+\mathrm{PW}$ is the best rule for the minimization of mean tardiness at low breakdown level for both tight and loose due dates with WTIS/(TPT-RPT) and (WTIS/PT) $\min$ as the next best rules. However, at high breakdown level PT+PW performs poorly. Rule (WTIS/PT) max $_{\text {in }}$ is the best rule for minimization of mean tardiness at high breakdown level for both tight and loose due dates with (WTIS) $)_{\max }$, (WTIS/PT) $)_{\min }$ and WTIS/(TPT-RPT) as the next best rules. Figs. 3 \& 4 show the effect of the percentage of time the machine suffers failure (breakdown level) on the absolute value of mean tardiness yielded by 11 dispatching rules. For both tight and loose due dates the mean tardiness increases with increasing breakdown level. For the minimization of maximum tardiness for both tight and loose due dates, ODD and EDD are the best rules and breakdown levels do not affect their relative performances. 
Singh, Mehta, Jain: Tardiness Based New Dispatching Rules for Shop Scheduling with ...

Table IV: RPI values of 11 dispatching rules at $\mathrm{BL}_{\mathrm{s}}=(0 \%, 2.5 \%$ and $5 \%)$ and $\mathrm{MTTR}=2.5 \bar{P}$.

\begin{tabular}{|c|c|c|c|c|c|c|c|c|c|}
\hline \multirow[t]{2}{*}{ Rule } & \multicolumn{3}{|l|}{$\mathrm{BL}_{\mathrm{s}}=0$} & \multicolumn{3}{|c|}{$\mathrm{BL}_{\mathrm{s}}=2.5$} & \multicolumn{3}{|l|}{$\mathrm{BL}_{\mathrm{s}}=5$} \\
\hline & $\operatorname{RPI}(\bar{T})$ & $\begin{array}{l}\text { RPI } \\
\left(T_{\max }\right)\end{array}$ & $\% \mathrm{~N}_{\mathrm{t}}$ & $\operatorname{RPI}(\bar{T})$ & $\begin{array}{l}\mathrm{RPI} \\
\left(T_{\max }\right)\end{array}$ & $\% \mathrm{~N}_{\mathrm{t}}$ & $\operatorname{RPI}(\bar{T})$ & $\begin{array}{l}\mathrm{RPI} \\
\left(T_{\max }\right)\end{array}$ & $\% \mathrm{~N}_{\mathrm{t}}$ \\
\hline \multicolumn{10}{|l|}{$C=3$} \\
\hline $\mathrm{PT}+\mathrm{PW}$ & 0 & 251.22 & 46.33 & 0.13 & 211.53 & 53.78 & 18.88 & 220.49 & 60.89 \\
\hline WTIS/(TPT-RPT) * & 2.62 & 262.58 & 35.21 & 3.89 & 223.69 & 42.52 & 13.92 & 226.29 & 48.35 \\
\hline (WTIS/PT)min* & 15.35 & 248.80 & 38.48 & 0 & 217.43 & 44.44 & 7.26 & 219.95 & 51.0 \\
\hline (WTIS)max* & 49.43 & 238.30 & 68.05 & 6.44 & 203.63 & 81.10 & 4.60 & 158.25 & 88.09 \\
\hline (WTIS/PT)max* & 68.91 & 221.03 & 71.90 & 7.38 & 172.12 & 81.37 & 0 & 144.15 & 87.98 \\
\hline $\begin{array}{l}\mathrm{ODD}+(\mathrm{WTIS} /(\mathrm{TPT}- \\
\mathrm{RPT})) *\end{array}$ & 175.09 & 19.56 & 93.63 & 126.17 & 19.73 & 95.65 & 133.17 & 16.50 & 96.38 \\
\hline $\mathrm{PT}+\mathrm{PW}+\mathrm{ODD}$ & 182.77 & 63.90 & 92.31 & 123.48 & 61.27 & 94.78 & 127.36 & 62.01 & 96.90 \\
\hline ODD & 186.89 & 0 & 94.84 & 126.57 & 0 & 95.83 & 128.08 & 0 & 96.80 \\
\hline EDD & 193.44 & 0 & 92.88 & 129.39 & 1.09 & 94.81 & 128.69 & 1.54 & 56.67 \\
\hline SPT & 212.17 & 171.34 & 47.37 & 106.57 & 142.66 & 59.44 & 81.35 & 127.99 & 68.56 \\
\hline FIFO & 224.15 & 37.53 & 90.47 & 153.15 & 42.33 & 93.34 & 155.44 & 44.62 & 95.04 \\
\hline \multicolumn{10}{|l|}{$C=6$} \\
\hline $\mathrm{PT}+\mathrm{PW}$ & 0 & 258.46 & 26.85 & 2.30 & 215.43 & 35.50 & 38.23 & 232.16 & 43.99 \\
\hline WTIS/(TPT-RPT) * & 11.7 & 270.21 & 18.95 & 13.54 & 227.88 & 26.47 & 40.77 & 238.40 & 32.90 \\
\hline (WTIS/PT)min* & 22.19 & 255.97 & 21.51 & 7.02 & 221.55 & 28.06 & 33.03 & 231.62 & 34.46 \\
\hline $\begin{array}{l}\mathrm{ODD}+(\mathrm{WTIS} /(\mathrm{TPT}- \\
\mathrm{RPT})) *\end{array}$ & 86.65 & 20.04 & 86.77 & 72.21 & 20.60 & 71.06 & 116.79 & 25.04 & 93.96 \\
\hline ODD & 88.77 & 0.94 & 90.24 & 65.29 & 0 & 92.93 & 105.08 & 0.89 & 94.68 \\
\hline (WTIS/PT)max* & 94.26 & 227.95 & 39.33 & 0.30 & 175.57 & 58.56 & 0 & 152.70 & 90.49 \\
\hline (WTIS)max* & 95.01 & 245.76 & 32.92 & 0 & 207.78 & 57.28 & 3.50 & 167.24 & 72.69 \\
\hline EDD & 95.76 & 0 & 87.37 & 70.21 & 0.55 & 91.20 & 104.41 & 0 & 92.84 \\
\hline $\mathrm{PT}+\mathrm{PW}+\mathrm{ODD}$ & 101.10 & 65.71 & 82.08 & 75.12 & 65.27 & 88.48 & 108.39 & 68.63 & 91.49 \\
\hline FIFO & 117.90 & 38.60 & 85.01 & 88.76 & 42.71 & 89.02 & 130.93 & 48.54 & 91.85 \\
\hline SPT & 174.81 & 176.77 & 34.20 & 97.09 & 145.36 & 44.31 & 107.29 & 135.88 & 52.07 \\
\hline
\end{tabular}

(* Newly proposed dispatching rules)

Mean tardiness for $c=6$

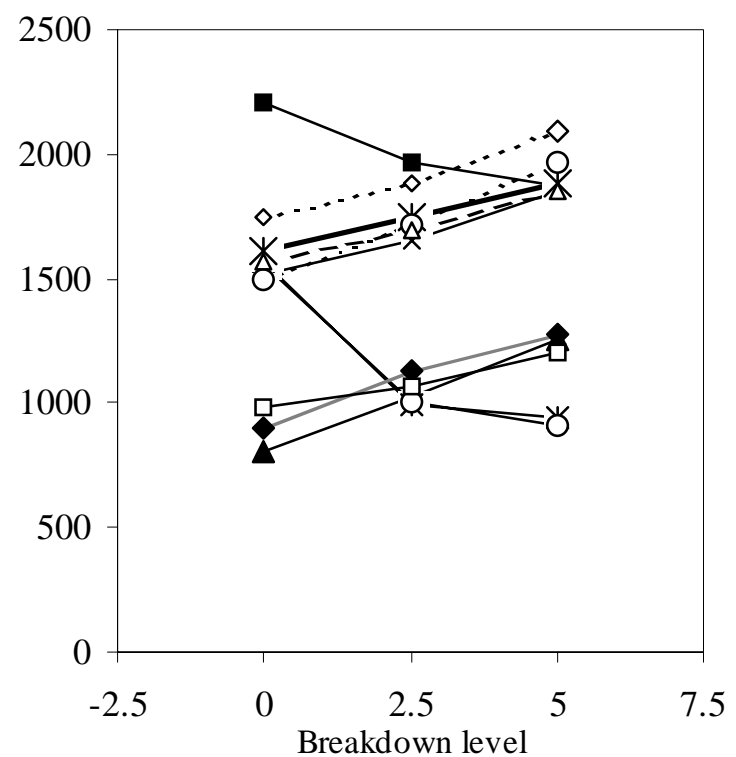

Figure 3: Mean tardiness vs. Breakdown level

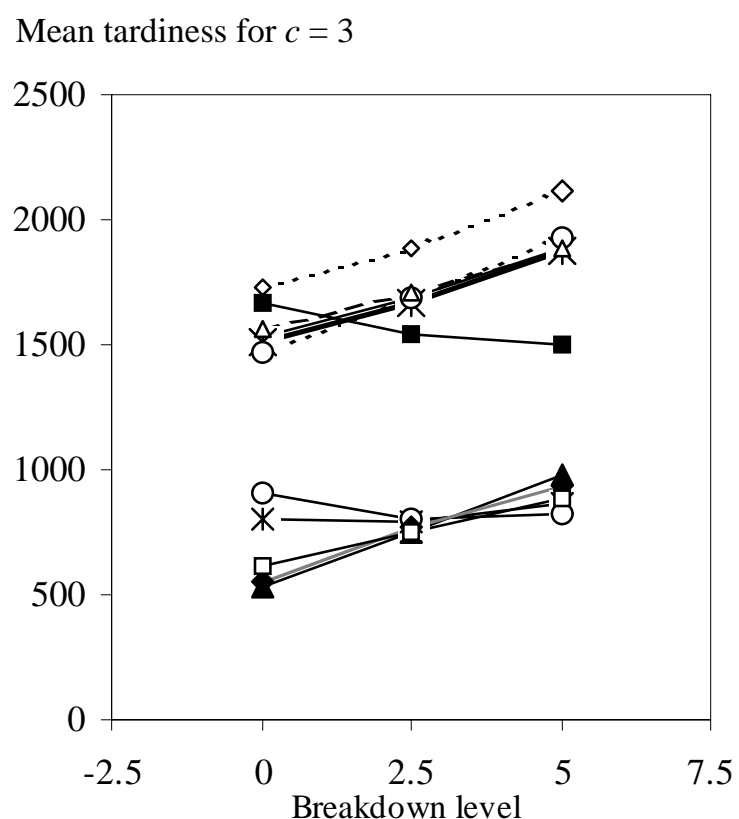

Figure 4: Mean tardiness vs. Breakdown level

\begin{tabular}{|c|c|c|}
\hline$\cdots \diamond \cdots$ FIFO & $\longrightarrow-\mathrm{SPT}$ & $\longrightarrow \mathrm{PT}+\mathrm{PW}$ \\
\hline$-x-$ ODD & 一*-(WTIS)max & $\longrightarrow$ - (WTIS/PT)max \\
\hline$\bullet$ WTIS/TPT-RPT & 一 $*$ - $\mathrm{PT}+\mathrm{PW}+\mathrm{ODD}$ & $\cdots$ - - - ODD+WTIS/TPT-RPT \\
\hline$-\Delta--E D D$ & ——(WTIS/PT)min & \\
\hline
\end{tabular}

For minimizing the number of tardy jobs, at low as well as high breakdown levels WTIS/(TPT-RPT) is the best rule with (WTIS/PT) $\min$ as the second best. The relative performance of these rules is not affected by the breakdown levels with respect to tight as 
well as loose due dates. However, the absolute value of percentage of tardy jobs increases with the increasing rate of breakdown level as shown in Figs. $5 \& 6$. The performance analysis of 11 dispatching rules for tardiness based objectives at three breakdown levels indicates that the relative performance of a rule can be affected by the percentage of time the machine suffers failure and yields larger value of an objective.

\subsection{Effect of MTTR on the performance of dispatching rules}

In this section the effect of mean time to repair on the performance of dispatching rules has been analysed by considering three values of mean time to repair MTTR (i.e. $\bar{P}, 2.5 \bar{P}$ and $5 \bar{P}$ ) for a fixed value of breakdown level (i.e. $2.5 \%$ ). Two values for due date tightness (i.e. $C=3$ for tight due dates and $C=6$ for loose due dates) have been considered.

Table V: RPI values of 11 dispatching rules at MTTR $=(\vec{P}, 2.5 \vec{P}$ and $5 \bar{P})$ and $\mathrm{BL}_{\mathrm{s}}=2.5 \%$.

\begin{tabular}{|c|c|c|c|c|c|c|c|c|c|}
\hline \multirow[t]{2}{*}{ Rule } & \multicolumn{3}{|c|}{$\operatorname{MTTR}=\bar{P}$} & \multicolumn{3}{|c|}{ MTTR $=2.5 \bar{P}$} & \multicolumn{2}{|c|}{$\mathrm{MTTR}=5 \bar{P}$} & \multirow[b]{2}{*}{$\% \mathrm{~N}_{\mathrm{t}}$} \\
\hline & $\operatorname{RPI}(\bar{T})$ & $\begin{array}{l}\mathrm{RPI} \\
\left(T_{\text {max }}\right)\end{array}$ & $\% \mathrm{~N}_{\mathrm{t}}$ & $\operatorname{RPI}(\bar{T})$ & $\begin{array}{l}\mathrm{RPI} \\
\left(T_{\text {max }}\right)\end{array}$ & $\% \mathrm{~N}_{\mathrm{t}}$ & $\operatorname{RPI}(\bar{T})$ & $\begin{array}{l}\text { RPI } \\
\left(T_{\text {max }}\right)\end{array}$ & \\
\hline \multicolumn{10}{|l|}{$C=3$} \\
\hline (WTIS/PT)max* & 0 & 208.31 & 79.92 & 7.38 & 172.12 & 81.37 & 23.37 & 175.97 & 82.60 \\
\hline (WTIS)max* & 2.30 & 194.68 & 78.25 & 6.44 & 203.63 & 81.10 & 8.14 & 175.13 & 81.16 \\
\hline WTIS/(TPT-RPT) * & 2.61 & 248.56 & 41.04 & 3.89 & 223.69 & 42.52 & 0 & 238.73 & 43.18 \\
\hline $\mathrm{PT}+\mathrm{PW}$ & 6.77 & 221.57 & 52.55 & 0.13 & 211.53 & 53.78 & 11.09 & 235.03 & 55.27 \\
\hline (WTIS/PT)min* & 15.56 & 228.17 & 43.42 & 0 & 217.43 & 44.44 & 2.59 & 214.36 & 45.77 \\
\hline SPT & 150.44 & 156.03 & 54.89 & 106.57 & 142.66 & 59.44 & 78.74 & 138.76 & 60.41 \\
\hline $\begin{array}{l}\mathrm{ODD}+(\mathrm{WTIS} /(\mathrm{TPT}- \\
\mathrm{RPT})) *\end{array}$ & 163.02 & 19.08 & 95.68 & 126.17 & 19.73 & 95.65 & 102.95 & 16.51 & 92.29 \\
\hline $\mathrm{PT}+\mathrm{PW}+\mathrm{ODD}$ & 163.94 & 66.48 & 94.89 & 123.48 & 61.27 & 94.78 & 105.43 & 66.70 & 94.77 \\
\hline ODD & 165.02 & 1.0 & 95.93 & 126.57 & 0 & 95.83 & 104.36 & 0 & 96.09 \\
\hline EDD & 169.33 & 0 & 94.88 & 129.39 & 1.09 & 94.81 & 113.22 & 2.42 & 95.10 \\
\hline FIFO & 197.84 & 56.14 & 92.52 & 153.15 & 42.33 & 93.34 & 129.98 & 38.71 & 92.72 \\
\hline \multicolumn{10}{|l|}{$C=6$} \\
\hline (WTIS/PT)max* & 0 & 219.05 & 50.87 & 0.30 & 175.57 & 58.56 & 11.81 & 183.87 & 62.79 \\
\hline (WTIS)max* & 8.69 & 204.89 & 47.70 & 0 & 207.78 & 57.28 & 0 & 183.03 & 61.34 \\
\hline $\mathrm{PT}+\mathrm{PW}$ & 10.70 & 232.67 & 32.93 & 2.30 & 215.43 & 35.50 & 8.79 & 245.03 & 38.97 \\
\hline WTIS/(TPT-RPT) * & 14.26 & 260.77 & 23.95 & 13.54 & 227.88 & 26.47 & 3.37 & 248.72 & 28.60 \\
\hline (WTIS/PT)min* & 27.20 & 239.33 & 25.83 & 7.02 & 221.55 & 28.06 & 7.28 & 247.57 & 30.55 \\
\hline ODD & 88.07 & 2.81 & 92.63 & 65.29 & 0 & 92.93 & 55.77 & 5.50 & 92.91 \\
\hline $\begin{array}{l}\mathrm{ODD}+(\mathrm{WTIS} /(\mathrm{TPT}- \\
\mathrm{RPT})) *\end{array}$ & 90.63 & 22.89 & 90.47 & 72.21 & 20.60 & 71.06 & 48.57 & 16.74 & 90.59 \\
\hline EDD & 92.41 & 0 & 90.35 & 70.21 & 0.55 & 91.20 & 50.17 & 0 & 90.86 \\
\hline $\mathrm{PT}+\mathrm{PW}+\mathrm{ODD}$ & 93.19 & 69.14 & 88.18 & 75.12 & 65.27 & 88.48 & 59.32 & 69.53 & 88.47 \\
\hline FIFO & 118.06 & 42.97 & 87.22 & 88.76 & 42.71 & 89.02 & 71.75 & 41.24 & 89.03 \\
\hline SPT & 158.30 & 158.81 & 38.35 & 97.09 & 145.36 & 44.31 & 62.07 & 145.22 & 47.58 \\
\hline
\end{tabular}

(* Newly proposed dispatching rules)

Table $\mathrm{V}$ presents the relative percentage increase (RPI) in mean tardiness, maximum tardiness and number of tardy jobs for each dispatching rule with respect to the best rule at various values of MTTR. At low value of mean time to repair, (WTIS/PT) $\max$ is the best rule

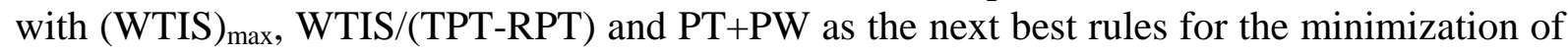
mean tardiness for tight due date settings. However for loose due date settings (WTIS/PT) $\max$ followed by (WTIS) $\max , \mathrm{PT}+\mathrm{PW}$ and WTIS/(TPT-RPT) are the best rules at low value of mean time to repair. At higher value of mean time to repair, WTIS/(TPT-RPT) is the best rule for the minimization of mean tardiness and (WTIS/PT) $\min$ and (WTIS) $\max$ are the next best rules for tight due dates. However for loose due dates (WTIS) $\max$ followed by WTIS/(TPT$\mathrm{RPT})$ and (WTIS/PT) $)_{\min }$ are the best rules at higher value of mean time to repair. Figs. 5 \& 6 illustrate the effect of mean time to repair on the absolute value of mean tardiness that increases with the increasing rate of MTTR. Mean time to repair affects the relative performance of the dispatching rules with respect to the maximum tardiness as shown in Table V. At low value of mean time to repair EDD is the best rule and ODD is the next best rule for tight as well as loose due date settings. At higher value of mean time to repair ODD is 
the best rule and EDD is the next best rule for tight due dates. In case of loose due dates EDD followed by ODD and ODD+(WTIS/(TPT-RPT)) are the best rules in the minimization of maximum tardiness.

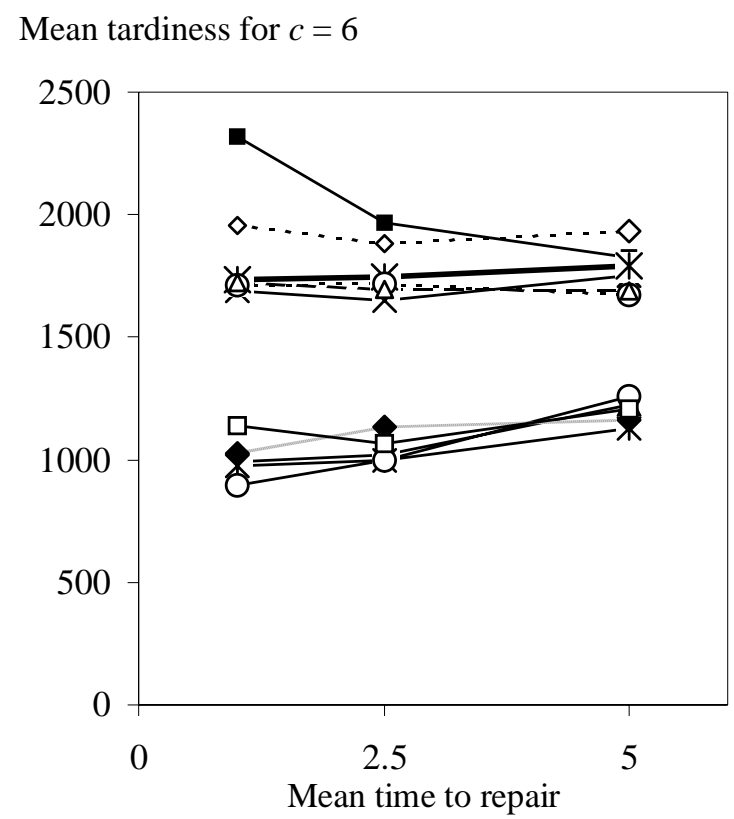

Figure 5: Mean tardiness vs. Mean time to repair

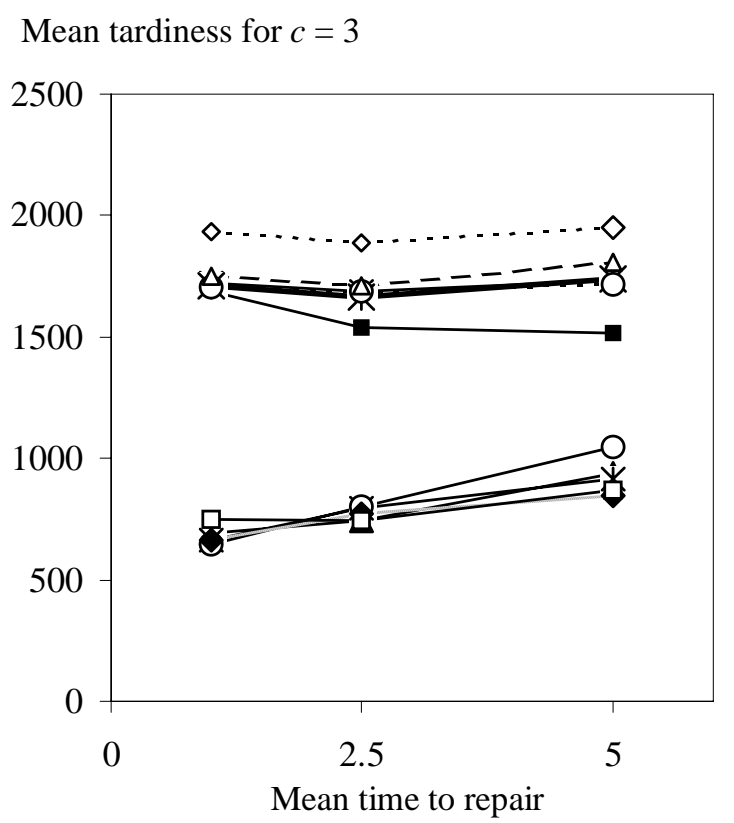

Figure 6: Mean tardiness vs. Mean time to repair

\begin{tabular}{|c|c|c|}
\hline$\cdots \diamond \cdots$ FIFO & $\longrightarrow$-SPT & $\longrightarrow \mathrm{PT}+\mathrm{PW}$ \\
\hline$-x-O D D$ & 一*-(WTIS)max & ——(WTIS/PT)max \\
\hline$\bullet$ WTIS/TPT-RPT & 一 $*$-PT+PW+ODD & $\cdots$ - $\cdots$ ODD+WTIS/TPT-RPT \\
\hline$--\Delta--E D D$ & ——(WTIS/PT)min & \\
\hline
\end{tabular}

In the minimization of percentage of tardy jobs, WTIS/(TPT-RPT) is the best rule and (WTIS/PT) $)_{\min }$ is the next best rule for tight as well as loose due dates at all values of mean time to repair. From the above discussion it can be concluded that increasing rate of mean time to repair can affect the relative performances of the dispatching rule and also increase the absolute value of an objective with respect to the tardiness based objectives.

\section{CONCLUSION}

In this paper the comparative study of dispatching rules has been carried out in the presence of varied rate of breakdown levels, mean time to repair and shop loading. During analysis it has been observed that the breakdown level, mean time to repair and shop loading affect the relative performance of most of the rules and an increase in the absolute value of tardiness based objectives (i.e. $\bar{T}, T_{\max }$ and $\% \mathrm{~N}_{\mathrm{t}}$ ) with the increase in the values of these input variables is also observed. Hence, the choice of the dispatching rule for the minimization of various performance measures not only depends on the performance measures itself but also on the breakdown and shop loading parameters. With respect to due date-based objectives the ranking of the dispatching rules have been summarized in Table VI for tight as well as loose due dates respectively. It is important to mention that no rule can be singled out as best under varying operating conditions. However, the rankings given in Table VI can be used as guidelines for selecting an appropriate dispatching rule for given operating conditions. Further, this research needs more investigation, particularly with respect to other values of 
operating conditions such as part mix, part complexity and other failure patterns. This research work can also be extended for the minimization of flow time based and tardiness based performance measures simultaneously. Presently authors are investigating these problems of dynamic scheduling by using a multi-objective approach.

Table VI: Ranking of dispatching rules based on shop parameters and in the minimization of an objective function.

\begin{tabular}{|c|c|c|c|c|c|c|c|c|}
\hline \multirow{2}{*}{ 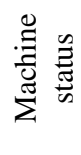 } & \multirow{2}{*}{ 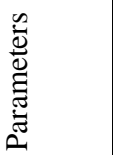 } & \multirow{2}{*}{ 䒕 } & \multicolumn{3}{|c|}{ For tight due dates } & \multicolumn{3}{|c|}{ For loose due dates } \\
\hline & & & Mean tardiness & $\begin{array}{l}\text { Maximum } \\
\text { tardiness }\end{array}$ & $\begin{array}{l}\text { Percentage of } \\
\text { tardy jobs }\end{array}$ & Mean tardiness & $\begin{array}{c}\text { Maximum } \\
\text { tardiness }\end{array}$ & $\begin{array}{l}\text { Percentage of } \\
\text { tardy jobs }\end{array}$ \\
\hline$\sum_{0}^{0}$ & 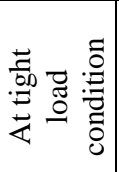 & 2 & $\begin{array}{l}\text { (WTIS)max* } \\
\text { (WTIS/PT)max* } \\
\text { Q* }\end{array}$ & $\begin{array}{l}\text { EDD } \\
\text { ODD } \\
\mathrm{R} *\end{array}$ & $\begin{array}{l}\text { Q* } \\
\text { (WTIS/PT)min* } \\
\text { SPT }\end{array}$ & $\begin{array}{l}\text { (WTIS)max* } \\
\text { (WTIS/PT)max* } \\
\text { Q* }\end{array}$ & $\begin{array}{l}\text { EDD } \\
\text { ODD } \\
\mathrm{R} *\end{array}$ & $\begin{array}{l}\text { Q* } \\
\text { (WTIS/PT)min* } \\
\text { PT+PW }\end{array}$ \\
\hline 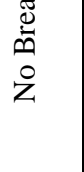 & 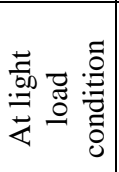 & 1 & $\begin{array}{l}\text { Q* } \\
\mathrm{PT}+\mathrm{PW} \\
\text { (WTIS/PT)min* }\end{array}$ & $\begin{array}{l}\text { EDD } \\
\text { ODD } \\
\mathrm{R} *\end{array}$ & $\begin{array}{l}\mathrm{Q} * \\
\text { (WTIS/PT)min* } \\
\mathrm{PT}+\mathrm{PW}\end{array}$ & $\begin{array}{l}\text { ODD } \\
\text { Q* } \\
\text { EDD }\end{array}$ & $\begin{array}{l}\text { EDD } \\
\text { ODD } \\
\mathrm{R} *\end{array}$ & $\begin{array}{l}\mathrm{Q} * \\
\text { (WTIS/PT)min* } \\
\mathrm{PT}+\mathrm{PW}\end{array}$ \\
\hline \multirow{4}{*}{ 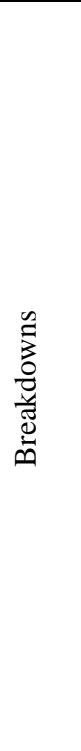 } & 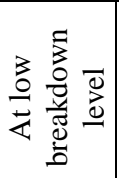 & 2 & $\begin{array}{l}\mathrm{PT}+\mathrm{PW} \\
\mathrm{Q} * \\
\text { (WTIS/PT)min* }\end{array}$ & $\begin{array}{l}\text { ODD } \\
\text { EDD } \\
\mathrm{R} *\end{array}$ & $\begin{array}{l}\mathrm{Q} * \\
\text { (WTIS/PT)min* } \\
\mathrm{PT}+\mathrm{PW}\end{array}$ & $\begin{array}{l}\mathrm{PT}+\mathrm{PW} \\
\mathrm{Q} * \\
\text { (WTIS/PT)min* }\end{array}$ & $\begin{array}{l}\text { EDD } \\
\text { ODD } \\
\mathrm{R} *\end{array}$ & $\begin{array}{l}\mathrm{Q} * \\
(\mathrm{WTIS} / \mathrm{PT}) \mathrm{min} * \\
\mathrm{PT}+\mathrm{PW}\end{array}$ \\
\hline & 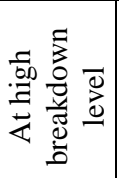 & 2 & $\begin{array}{l}\text { (WTIS/PT)max* } \\
\text { (WTIS)max* } \\
\text { (WTIS/PT)min* }\end{array}$ & $\begin{array}{l}\text { ODD } \\
\text { EDD } \\
\mathrm{R} *\end{array}$ & $\begin{array}{l}\text { Q* } \\
\text { (WTIS/PT)min* } \\
\mathrm{PT}+\mathrm{PW}\end{array}$ & $\begin{array}{l}\text { (WTIS/PT)max* } \\
\text { (WTIS)max* } \\
\text { (WTIS/PT)min* }\end{array}$ & $\begin{array}{l}\text { EDD } \\
\text { ODD } \\
\mathrm{R} *\end{array}$ & $\begin{array}{l}\text { Q* } \\
\text { (WTIS/PT)min* } \\
\mathrm{PT}+\mathrm{PW}\end{array}$ \\
\hline & 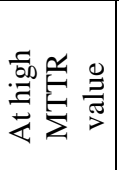 & 2 & $\begin{array}{l}\text { Q* } \\
\text { (WTIS/PT)min* } \\
\text { (WTIS)max* }\end{array}$ & $\begin{array}{l}\text { ODD } \\
\text { EDD } \\
\mathrm{R} *\end{array}$ & $\begin{array}{l}\text { Q* } \\
\text { (WTIS/PT)min* } \\
\mathrm{PT}+\mathrm{PW}\end{array}$ & $\begin{array}{l}\text { (WTIS)max* } \\
\text { Q* } \\
\text { (WTIS/PT)min* }\end{array}$ & $\begin{array}{l}\text { EDD } \\
\text { ODD } \\
\mathrm{R} *\end{array}$ & $\begin{array}{l}\mathrm{Q} * \\
\text { (WTIS/PT)min* } \\
\mathrm{PT}+\mathrm{PW}\end{array}$ \\
\hline & 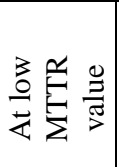 & 2 & $\begin{array}{l}\text { (WTIS/PT)max* } \\
\text { (WTIS)max* } \\
\text { Q* }\end{array}$ & $\begin{array}{l}\text { EDD } \\
\text { ODD } \\
\mathrm{R} *\end{array}$ & $\begin{array}{l}\text { Q* } \\
\text { (WTIS/PT)min* } \\
\text { PT+PW }\end{array}$ & $\begin{array}{l}\text { (WTIS/PT)max* } \\
\text { (WTIS)max* } \\
\text { PT+PW }\end{array}$ & $\begin{array}{l}\text { EDD } \\
\text { ODD } \\
\mathrm{R} *\end{array}$ & $\begin{array}{l}\mathrm{Q} * \\
(\mathrm{WTIS} / \mathrm{PT}) \mathrm{min} * \\
\mathrm{PT}+\mathrm{PW}\end{array}$ \\
\hline
\end{tabular}

(* Newly proposed dispatching rules) $(\mathrm{Q}=\mathrm{WTIS} /(\mathrm{TPT}-\mathrm{RPT}), \mathrm{R}=\mathrm{ODD}+\mathrm{WTIS} /(\mathrm{TPT}-\mathrm{RPT}))$

\section{REFERENCES}

[1] Miyazaki, S. (1981). Combined scheduling system for reducing job tardiness in a job shop, International Journal of Production Research, Vol. 19, No. 1, 201-211

[2] Blackstone, J. H.; Phillips, D. T.; Hogg, G. L. (1982). A state of the art survey of dispatching rules for manufacturing job shop operations, International Journal of Production Research, Vol. 20, No. 1, 27-45

[3] Baker, K. R.; Bertrand, J. W. M. (1982). A dynamic priority rule for sequencing against due date, Journal of Operations Management, Vol. 3, 37-42

[4] Baker, K. R.; Kanet, J. J. (1983). Job shop scheduling with modified due dates, Journal of Operations Management, Vol. 4, 11-22 
[5] Kanet, J. J.; Hayya, J. G. (1981). Priority dispatching with operation due dates in a job shop, Journal of Operations Management, Vol. 2, 167-176

[6] Russell, R. S.; Darel, E. M.; Taylor, B. W. (1987). A comparative analysis of the covert job sequencing rule using various shop performance measures, International Journal of Production Research, Vol. 25, No.10, 523-1540

[7] Raghu, T. S.; Rajendran, C. (1993). An efficient dynamic dispatching rule for scheduling in a job shop, International Journal of Production Economics, Vol. 32, No. 3, 301-313

[8] Anderson, E. J.; Nyirendra, J. C. (1990). Two new dispatching rules to minimize tardiness in a job shop, International Journal of Production Research, Vol. 28, No. 12, 2277-2292

[9] Jayamohan, M. S.; Rajendran, C. (2000). New dispatching rules for shop scheduling: a step forward, International Journal of Production Research, Vol. 38, No. 3, 563-586

[10] Rajendran, C.; Holthaus, O. (1999). A comparative study of dispatching rules in a dynamic flow-shops and job-shops, European Journal of Operational Research, Vol. 116, 156-170

[11] Sabuncuoglu, I.; Hommertzheim, D. (1992). Experimental investigation of FMS machine and AGV scheduling rules against the mean flow-time criterion, International Journal of Production Research, Vol. 30, No. 7, 1617-1635

[12] Sabuncuoglu, I. (1998). A Study of Scheduling Rules of Flexible Manufacturing System: A Simulation Approach, International Journal of Production Research, Vol. 36, No. 2, 527-546

[13] Kutanoglu, E.; Sabuncuoglu, I. (1999). An analysis of heuristics in a dynamic job shop with weighted tardiness objectives, International Journal of Production Research, Vol. 37, No. 1, 165-187

[14] Holthaus, O. (1999). Scheduling in job-shop with machine breakdowns: an experimental study, Computers \& Industrial Engineering, Vol. 36, 137-162

[15] Denzler, D. R.; Boe, W. J. (1987). Experimental Investigation of Flexible Manufacturing System Scheduling Decision Rules, International Journal of Production Research, Vol. 25, No. 7, 979-994

[16] Rajendran, C. (1994). A heuristic for flow shop and flow line based manufacturing cell with multicriteria, International Journal of Production Research, Vol. 32, No. 11, 2541-2558

[17] Holthaus, O.; Rajendran, C. (1997). Efficient dispatching rules for scheduling in a job shop, International Journal of Production Economics, Vol. 48, 87-105

[18] Panwalker, S. S.; Iskander, W. (1997). A survey of scheduling rules, Operation Research, Vol. 25, No. 1, 49-61

[19] Conway Richard W.; Maxwell William L.; Miller Louis W. (1967). Theory of Scheduling, Addition-Werley publishing company

[20] Law, A. M.; Kelton, W. D. (2000). Simulation Modeling and Analysis, Third Edition, McGrawHill, New-York

[21] Haupt, R. (1989). A survey of priority rule based dispatching, O.R. Spektrum, Vol. 11, 3-16

[22] Ramasesh, R. (1990). Dynamic job shop scheduling: a survey of simulation research, OMEGA, Vol. 16, 43-57 